\title{
CORPOS NEGROS NO TRONO: negritude em espaço de poder
}

\author{
Marcelo Máximo Purificação ${ }^{1}$ \\ Lousana de Jesus Santana²
}

\author{
${ }^{1}$ Fundação Integrada Municipal de Ensino Superior (FIMES-UNIFIMES) - Mineiros, GO, Brasil. \\ 2 Bosista da Fundação de Amparo a Pesquisa do Estado da Bahia,, Brasil.
}

Como citar: PURIFICAÇÃO, M.M.; SANTANA, L. J. CORPOS NEGROS NO TRONO: negritude em espaço de poder. Revista Científica Novas Configurações - Diálogos Plurais, Luziânia, v. 1, n.1, p. 1-3, 2020. https://doi.org/10.4322/26754177.2020 .001

Este texto aproxima-se da lupa teórica dos estudos culturais para, por meio do diálogo e da reflexão, discutir temas como (anti) racismo, identidade e representações da negritude na sociedade contemporânea. Os discursos que ecoam das ruas, guetos e espaços de militância negra, trazem a máxima de que "não há negros em espaços de poder" e "os negros precisam conquistar os espaços de poder" (SANTANA, PURIFICAÇÃO, TORRES, 2019, p.9). Parto das primícias de que existem aspectos (in) visíveis norteando esses discursos, e que esses perpassam contextos políticos, sociais, econômicos e culturais. Na linha dessas ideias, trago como artefato de análise a "Campanha do Dia dos Pais, do Boticário"- onde uma família negra assume o papel de protagonistas. O fato poderia ter passado despercebido e ser mais um entre as dezenas de comerciais de empresas que vendem seus produtos utilizando como signo a família. Mas, o que diferencia a campanha do dia dos pais do Boticário das campanhas de margarina que de tempo em tempo aparecem na televisão brasileira? Talvez a resposta para essa indagação esteja no fato de não ser uma propaganda habitual e não vermos com certa frequência o negro protagonizar comerciais/propagandas na tv. Por isso, campanhas desse tipo, quando aparecem, são sempre alvo de discursos preconceituosos e pejorativos de uma parcela da comunidade, que se apresenta como defensora da representatividade.

Como negro, sinto-me muito feliz com a abertura de espaços de poder na mídia para a comunidade negra, uma vez que, por anos a fio acompanhamos a trajetória do negro na televisão brasileira e, na maioria das vezes em posições subalternas. Ainda sobre o comercial, me coloco também numa posição de atenção, diante do jogo de paradoxos que o mesmo pode introduzir no imaginário da população negra do Brasil e excluir do imaginário coletivo desse grupo, o encanto do desejo de lutar contra as (des) - (des) igualdade, (des) valorização, etc.

Para corroborar essa concepção, trago as vozes de Guimarães (1999) que ecoando dizem: “As 'marcas' da negritude já não são simples marcações identitária, mas sim 'espaços' a serem '(des)colonizados'; trincheiras plurais” (p.21), compreende-se que a voz que emana do povo (em situação de minorias) geralmente luta pela (des)colonização desses espaços, o que desemboca em dilemas e tensões, pois no social as verdades já estão expostas e, nesse contexto, cada um olha de acordo com sua miopia.

Analisando o comercial por uma outra perspectiva, posso enfaticamente afirmar que ele me preocupa. Na verdade, me dá medo. Medo que esses 30 segundos de fama sejam utilizados como uma forma de legitimação do falso poder. Uma forma de apagar as mazelas sociais e colaborar para a

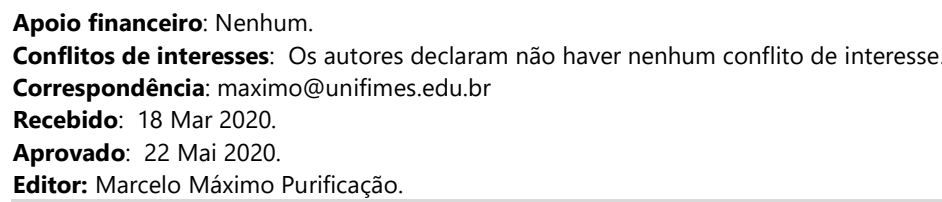


construção de uma suposta democracia social que venha invisibilizar a imagem de poder e liderança do branco sobre o negro e, com isso, validar e normatizar a supremacia de um grupo sobre o outro.

O confronto dos corpos (brancos e negros) surge como uma herança do processo de colonização, que legitimou o status de dominação de um grupo, e o de servidão e inferioridade do outro. O outro, aqui, é o negro que - historicamente falando-, atravessou vários contextos lutando por acesso de igualdade (de direitos e garantias fundamentais) a bens e serviços. Olhando as representações advindas dos corpos negros colocados no trono midiático, através do comercial do dia dos pais do Boticário, cito duas como sendo principais - identidade ${ }^{1}$ e raça -, que suscitam de forma (in) direta discussão sobre negritude, branquitude e mestiçagem. Subtende a partir das leituras de Hall (2013); Gilroy (2001); Gadea (2013); Santos e Falcão (2018) que as questões oriundas das discussões sobre identidade e raça se reconfiguram na disputa simbólica, pois são gestadas muitas vezes, dentro de processos de ambiguidade e "dentro de processos ambíguos, críticos e dialógicos, há lugares de falas, alguns legitimados, outros em busca de legitimação. Nesses processos, também há narrativas que se entrecruzam, assim como há as que silenciam, excluem e filtram memórias" (SANTOS e FALCÃO, 2018, p.455). Desse confronto de corpos, outras representações emergem, como por exemplo os discursos midiáticos de negritude, racismo e mídia, ações afirmativas, etc.

Diante do exposto e das reflexões geradas a partir das leituras indicadas e das complementares, levanto as seguintes provocações: por que o signo família vem sendo, há décadas, essecializado no contexto da sociedade do consumo? Que significados os corpos negros no trono midiático - no comercial do dia dos país do Boticário -, trazem em sua constituição? Que verdades essa representação simbólica suscitou?

E você, que agora lê este texto, quer saber mais um pouco sobre as constituições de verdade? Então, com a palavra, Carlos Drummond de Andrade, em seu poema "Verdade":

A porta da verdade estava aberta,

mas só deixava passar

meia pessoa de cada vez.

Assim não era possível atingir toda a verdade,

porque a meia pessoa que entrava

só trazia o perfil de meia verdade.

E sua segunda metade

voltava igualmente com meio perfil.

E os dois meios perfis não coincidiam.

Arrebentaram a porta. Derrubaram a porta.

Chegaram a um lugar luminoso

onde a verdade esplendia seus fogos.

Era dividida em duas metades,

diferentes uma da outra.

Chegou-se a discutir qual a metade mais bela.

As duas eram totalmente belas.

Mas carecia optar. Cada um optou conforme

seu capricho, sua ilusão, sua miopia (ANDRADE, 2002 grifo nosso).

\section{REFERÊNCIAS}

ANDRADE, C. D. Poesia completa. Rio de Janeiro: Nova Aguilar, 2002.

BARROS, Maria Luisa Mendes Santos. A Resistência da Negritude: descontruindo a mídia branca com inserção e resistência da negritude nos veículos de comunicação. IV Encontro Regional de

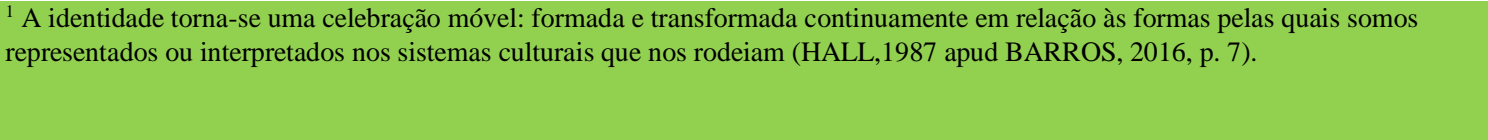


História da Mídia - Alcar, 2016. Universidade Federal Fluminense - Niteroi - RJ. Disponível em: file:///E:/MEUS\%20DOCUMENTOS/Downloads/ma06.pdf. Acessado em 13/03/2020.

GADEA, Carlos A. Negritude e pós-africanidade: críticas das relações raciais contemporâneas. Porto Alegre: Sulina, 2013.

GILROY, Paul. Against Race: Imagining political culture beyond the color line. Harvard University Press, 2001.

GUIMARÃES, Antonio Sérgio A. Racismo e anti-racismo no Brasil. São Paulo: Editora 34, 1999.

HALL, Stuart. Identidade cultural e diáspora. In: Revista do Patrimônio Histórico e Artístico Nacional. Rio de Janeiro, IPHAN, 1996, p. 68-75.

HALL, Stuart. Raça, o significante flutuante. ZCultural, Ano VIII, 02. Trad. Liv Sovik. Disponível em: Acesso em 05 de maio de 2013.

SANTANA, Lousana de Jesus. PURIFICAÇÃO, Marcelo Máximo; TORRES, Claudia Regina de Oliveira Vaz. Corpos negros no chão $x$ corpos negros no trono: espaços de poder e os negros no Brasil. RECH - Revista Ensino de Ciências e Humanidades - Cidadania, Diversidade e Bem-Estar. Ano 3, Vol. V, Número 2, jul. - Dez, 2019, p.8-19. Disponível em: http://periodicos.ufam.edu.br/index.php/rech/article/view/6788/4777. Acessado em 12/03/2020.

SANTOS, Kywza Joanna Fideles Pereira dos; FALCÃO, Carolina Cavalcanti. Que Negros E Negras São Esses (as) Do Youtube? Pensando a negritude e as formas de identidade a partir das narrativas exemplares. Dossiê Os Estudos Atorais - revistas.ufrj.br/index.php/eco_pos - ISSN 2175-8689 - v. 22 , n. 1, 2019. Disponível em: file:///E:/MEUS\%20DOCUMENTOS/Downloads/20378-65272-1PB\%20(3).pdf. Acessado em 12/03/2020.

Informações sobre os autores:

MMP: Pós-Doutor em Educação (UC). Professor permanente nos mestrados: PPG-Edu (FACMAIS), PPG-Edu (UEMS) e MPIES (UNEB). E-mail: maximo@ unifimes.edu.br

LJS: Graduada em Pedagogia e Mestranda (MPIES) UNEB. E-mail: lousanasantana@gmail.com

Contribuição dos autores: MMP; LJS: conceitualização, captação de recursos, supervisão, redação. 